\title{
Effect Of An Educational Program About Occupational Health And Safety On Knowledge, Attitude, And Practice Of Workers In Textile Factory In Damietta City
}

\author{
Ateya Megahed Ibrahim ${ }^{1}$ prof. Dr. Effat Mohamed El-Karmalawy ${ }^{2}$ \\ Associate. Prof.Mona Abd-Elsabour Hassan ${ }^{3}$ Dr. Fatma El-Emam Hafez ${ }^{4}$. \\ ${ }^{1}$ M.Sc. In Family And Community Health Nursing, Faculty Of Nursing, Port Said University. ${ }^{2}$ Professor Of \\ Community Health Nursing, Faculty Of Nursing, Cairo University. \\ ${ }^{3}$ Associate Professor Of Family And Community Health Nursing, Faculty Of Nursing, Port Said University. \\ ${ }^{4}$ Lecturer Of Family And Community Health Nursing, Faculty Of Nursing, Port Said University. \\ ABSTRACT
}

Background: Occupational Health and Safety is one of the most important aspects of human concern.

The aim of this study is to evaluate the effect of an educational program about Occupational Health and Safety on knowledge, attitude, and practice of workers in textile factory in Damietta City.

Sample: the study is carried on 108 workers.

Research design A quasi-experimental research design with pre-post assessment is utilized.

Data collection tools: data are collected using four tools: Workers' Structured Interview Questionnaire, Workers' Knowledge Questionnaire, Workers' Attitude Questionnaire, and Reported Practice Questionnaire.

Results: revealed that two-fifths (40.0\%) of the study group were between the ages of 46-60 years. The study group had poor total level of knowledge (92.6\%), negative attitude (100\%) as well as poor total practice (89.8\%) before conducting the educational program. A highly statistically significant improvement was detected after the implementation of the program in their total level of good knowledge (84.3\%), positive attitude (100\%), as well as their total good practices (63\%). There was a statistically significant positive correlation between the study group's total knowledge score and total practice score at $p<0.001$, while there was no statistically significant correlation between total attitude and total knowledge scores nor between total practice and total attitude scores of the study group.

Conclusion: The educational program is successful in attaining its aim of positively improving knowledge, attitude and practice of the study group about Occupational Health and Safety.

Recommendations: It is recommended to apply the International Standards of Occupational Health and Safety among workers in textile factories to improve their performance, educational materials about Occupational Health and Safety should be conducted and disseminated to raise workers' awareness and reduce the incidence of work related-hazards. Replication of similar specific studies using large probability samples at different settings is highly recommended.

Keywords: Occupational Health and Safety, Educational program, Textile factory.

\section{Introduction}

Throughout the globe, most adults and many children spend a great deal of their waking hours at work. The work provides a number of economic benefits. At the same time, people at work face a diversity of hazards owing to chemicals, biological factors, physical agents, adverse ergonomic conditions, allergens, a complex network of safety hazards, and diversified psychosocial agents. In addition to injuries, more than one hundred occupational diseases have been sorted according to the tenth revision of the International Rating of Diseases and Related Health Problems. Generally, these involve respiratory, musculoskeletal, cardiovascular, reproductive, neurotoxin, skin and psychological disorders, hearing loss and cancers (Friend\& Kohn, 2010; Nickitas et al, 2011; Guidotti et al., 2013).

The international labor organization (ILO) predestined that occupational accidents and work-related diseases induce over 2.3 million deaths per year, of which over 350,000 results from occupational accidents and close to 2 million from work- related diseases. In add-on to these fatalities, it is judged that there were over 313 million non-fatal occupational accidents) ILO, 2015). Furthermore, the World Health Organization (WHO) stipulated that workplace conditions reckoning for over a third of back pain, $16 \%$ of hearing loss, nearly $10 \%$ of lung cancer; and that $8 \%$ of the burden of depression. Moreover, Every three-and a half minutes, somebody in the European Union (EU) dies from workplace-associated lawsuits. This means nearly 167,000 deaths a year in Europe alone, as a moment of either work-related accidents $(7,500)$ or occupational diseases $(159,500)$ (Kun, 2014). 
A respectable and productive workforce is the central ingredient behind the societal and economic evolution of whatever country. Originally, occupational health programs were planned during the advent of industrialization to prevent and care for acute and continuing illness and injuries among the playing population. Gradually, as the public health plans were developed, occupational health adopted a more specific role in the prevention and control of occupationally determined outcomes, accidents and diseases directly associated with the work or operating conditions. Over time, occupational health shifted its emphasis to the overall health and welfare of the working populations (Guidotti, 2011).

The subject of Occupational Health and Safety is concerned with minimizing loss by aiding in the preservation and protection of both human and other physical assets in the workplace. The subject is far reaching in both range and pattern. It is essentially involves monitoring the workplace and advising employers or management on the best ways to prevent and minimize losses. Final responsibility for action always rests on the shoulders of the management, as they ultimately accountable for workplace behaviors.The job of occupational health and safety is to assist management by watching over the workplace and providing guidance (Friend \&Kohn, 2014).

Textile industry occupies a significant place among the basic requirements of human organisms. In that respect, there is an always a considerable need for high-quality materials at optimum cost around the globe.the globe. The textile industry is providing employment to numerous people around the world. The applications of textiles are versatile and now offers to technical materials, where function rather than an anesthetic is of main concern. Among the different sectors of the textile manufacturing process, the yarn manufacturing process is an important one, as it influences the last character of the fabric significantly, as considerably as the price of the fabric (Kumar, 2015).

The Occupational health nurse (OHN) plays a major role in helping to protect and better the health of working populations. The purpose of the role of $\mathrm{OHN}$ is to authorize employees to make informed health decisions while also overseeing the health dangers and costs connected with the employment relations between employees and the business (Guzys \& Petrie, 2014). The centering of the occupational health nurse is on keeping employees healthy, preventing illness and accidents and ensuring a safe business or industrial surroundings. The occupational health nurse is in an ideal situation to supply guidance, counseling, grooming, and coaching for employers who want to improve their health (Cooper \& Gosnell, 2015; Nies \& McEwen, 2015).

\section{Significance of the study}

Cotton industry workers are let out to various hazards in the different sections of textile factories, especially in the spinning and weaving sections which play a part in the high incidence of the industrial health hazards. The major health problems connected with cotton dust are respiratory problems, which include (byssinosis, bronchitis and bronchial asthma). The troubles are extremely prevalent in manufacturing plants in developing countries like, Egypt (Vastrad et al., 2013; Babel \&Tiwari, 2014; Khan et al., 2015). A study is conducted among workers in a textile factory in Port Said City revealed that more than three quarters (77\%) of the study group were exposed to psychological hazards and about two thirds (64\%) were exposed to physical hazards (Ibrahim, 2014).

The main goal of occupational wellness and safety is to promote the health and safety of people at work through prevention and early intervention (Miller, 2012; Estes, 2014). Occupational Health and Safety affect not only the worker, but also his family and his community. In addition, Occupational Health Nursing is the specialty practice that focuses on promotion, prevention, and restitution of health within the context of a secure and healthy environment, including prevention of adverse health effects from occupational and environmental hazards (McCullagh \& Berry, 2015). Therefore, the intent of the present study is to evaluate the effect of an educational program conducted for workers in the textile factory in Damietta City in order to improve their knowledge, practice, and attitude toward Occupational Safety, hence improve their health.

\section{Aim Of The Study}

To evaluate the effect of an educational health program about Occupational Health and Safety on knowledge, attitude and practice of workers in textile factory in Damietta City.

\section{Objectives}

1. Assess workers' knowledge, attitude and practice regarding Occupational Health and Safety.

2. Develop a health educational program for workers about Occupational Health and Safety.

3. Determine the effect of the health educational program on workers' health.

\section{Hypothesis}

1. Knowledge of the workers toward Occupational Health and Safety will be improved after implementation of the health educational program. 
2. The attitude of the workers toward Occupational Health and Safety will be improved after the implementation of the health educational program.

3. The practice of the workers toward Occupational Health and Safety will be improved after the implementation of the health educational program.

4. There will be statistically significant differences between level of education of the workers and total effect of the program.

\section{Study Design \& Setting}

\section{Subjects And Method}

The study is carried out using a quasi-experimental research design. It is conducted in the textile factory in Damietta City which consisted of three large wards namely (pretreatment and Fiber preparation wards, Spinning and weaving wards and Dyeing and printing wards).

\section{Total population}

Total number of workers in the textile factory were 120 workers

\section{Study Sample}

All workers in the textile factory (108 workers) were admitted in the study after exclusion of the pilot study (12 workers) from the entire sample size.

Tools of data collection: Data are collected using the following four tools.

Tool I: Workers' Structured Interview Questionnaire:

It is developed by the researcher and is composed of two main parts. The first part is developed to collect data related to socio-demographic characteristic of the textile factory workers: such as age, family numbers, marital status, level of education and monthly income. The second part includes questions related to work characteristics: such as work shifts, daily working hours, years of experience, and position during work.

\section{Tool II: Workers' Knowledge Questionnaire}

It is developed by the researcher to assess knowledge of the workers. This questionnaire is divided into two parts: the first part includes open ended questions about types of occupational hazards (physical, chemical, mechanical, and psychological ), risks from exposure to occupational hazards, safety measures to avoid occupational hazards exposure, and the second part which includes also open ended questions about personal protective equipment, concept and goals of occupational health program, effect of cotton dust and noise on workers' health, and ways to reduce effect of cotton dust and noise on workers' health. It was used twice immediately after completion of the program and after three months.

\section{Scoring system:}

The study group's answers were compared with a model key answers, where (2) score is given for completely correct answer, (1) for incompletely correct answer, and (0) for incorrect answer. These scores have converted into a percent score. Means and standard deviations are computed. The workers's knowledge is evaluated good if the percent score is $\geq 75 \%$, while considered average if the percent score is less than $75 \%$ and more than $50 \%$ and poor if the percent score is less than $50 \%$.

\section{TOOL (III): Workers' Attitude Questionnaire :}

A modified Likerat scale adopted from wall (2009) is utilized to assess workers' attitude regarding occupational hazards and safety measures using a health belief model which involved six domains (perceived susceptibility domain, perceived seriousness domain, perceived benefits domain, perceived barriers domain, cues to action domainand efficacy domain. The scale is measured on five point's Likerat Scales ranging from strongly agree, agree neutral, disagree, and strongly disagree respectively.

\section{Scoring system}

The total number of items is (35) each for pre-, post- and follow- up) and they are measured on five points Likerat scale ranging from 5,4,3,2 and 1 for responses: strongly agree, agree, neutral , disagree, and strongly disagree. Score of items is summed up with total score divided by number of items giving mean score for the attitude. Total score is converted into a percent score, and means and standard deviations were computed. The attitude is considered "Positive" if percent scores are $60 \%$ or more and "Negative" if less than $60 \%$ ). 


\section{TOOL (IV): Reported Practice Questionnaire:}

It is adapted from Shafik \& Abd El Mohsen (2012), to assess workers' practice regarding occupational hazards and safety measures. It is composed of (5) open ended questions. It includes questions about practice done in the cases of the eyes and exposure to chemical substances, swallowing of poisonous substances, falling, and bleeding.

\section{Scoring system}

Measuring the score of study group's practice toward occupational hazards are as follows: A known item is scored one point (1); an unknown item is scored zero (0). These scores are converted into mean, standard deviation and percent score. The workers practice is considered good: if the percent score is $\geq 75 \%$, while is considered fair if the percent is less than $75 \%$ and more than $50 \%$ and poor if percent score is less than $50 \%$.

\section{Tool Content Validity and Reliability:}

Tools of data collection are tested for content validity by a panel of five experts in the field of Community Health Nursing, Faculty of nursing (Cairo University), and Public Health, Faculty of Medicine (Mansoura University). It is conducted to test the tools for appropriateness, comprehensiveness, relevance, and clearance. Their opinions are elicited regarding the tool format, layout, and consistency. The necessary modifications are done accordingly.The reliability is assured by calculating cronbach's alpha coefficients for each factor, it was high (0.79).

\section{Pilot study}

The pilot study was carried out with $10 \%$ of study sample which included (12) workers, who were selected randomly from textile factory in Damietta city. It was done to ascertain the relevance, clarity \& applicability of the developed tool and to estimate the time needed to fill the questionnaire sheet. Those workers who shared in the pilot study were excluded from the main study sample as a result of the modifications made to the questionnaire sheet, where some of the questions were added and others were omitted and rewording. The final form of the tool was formulated and the time needed for completing them was also determined.

\section{Administrative and Ethical Considerations:}

An official permission is obtained by submission of an official letter from the Faculty of Nursing to the responsible authorities of the study setting to obtain the authorization for data collection. The aim of the study is explained to every worker before participation, and voluntary participation is emphasized and an oral consent is obtained.

\section{Statistical Analysis}

Data are fed to the computer and analyzed using IBMSPSS software package version 20.0. Qualitative data are described using numbers and percent. Quantitative data are described using range (minimum and maximum), mean, standard deviation and median.Significance of the obtained results is judged at the 5\% level.

\section{Field Work:}

The study is implemented through the following four phases: assessment, program development, implementation, and evaluation. Collection of the data covered a period of nine months from $1^{\text {st }}$ of November 2014 until the end of July 2015.

\section{Assessment Phase}

After preparing the tool, the study sample was recruited. This was followed by collecting baseline data. Pretested questionnaire was administered to the study sample to study their existing level of knowledge, attitude and practice regarding occupational health and safety. Data collected from the workers were performed during work breaks. Textile factory was visited three days/week from the beginning to the end of the work. The researcher introduced himself to the workers and took the consent of them to be recruited in the study after explaining the aim of the study, then the researcher interviewed textile workers and distributed the questionnaire sheet to them. During the interview, the researcher read each item/question on a data collection sheet and explained its meaning to the workers. Then the workers were asked to write down their answers. Each sheet lasted about 30 minutes to be filled. (For workers who couldn't read and write, questionnaire form was filled by the researcher). Confidentiality for all collected information was strictly assured. During this phase of the assessment, accurate observation has been done for the textile factory's environment. Those observations were displayed to the textile factory's directors with an emphasis on the importance of Cleanliness and safety of the work environment as it significantly affects the health of the workers hence their performance. 


\section{Program Development Phase}

Based on the information obtained from initial assessment, in addition to literature, the researcher designed the educational program under the guidance of the supervisors. A simple booklet was developed for workers, which covered all items related to Occupatinal Health and Safety. The educational booklet is written in a simple Arabic language with different illustrated color pictures. It included nine sessions. The first session covered some definitions of occupational health and safety. The second session included objectives of occupational health and safety program. The third session was concerned with types of occupational hazards faced textile workers. The fourth session involved preventive measures to reduce the impact of occupational hazards on workers' health. The fifth session covered causes and preventive measures of accidents in textile factories. The sixth session evolved first aids. The seventh session included causes of burn in textile factories and methods of prevention. The eighth covered health care, periodic examination and follow-up.The ninth and final session was concerned with types of health habits.

\section{Program Implementation Phase}

The participating workers were divided into eight groups of 12-15 each. The program was conducted through nine sessions; each group obtained three sessions /week, each session took about one hour. The total allocated time for achieving the whole program to the eight groups was 72 hours ( 8 groups $\times 9$ hours). At the beginning of the first session, an orientation to the aim of the study and the goals of the program took place. Also, workers were oriented about the phases of the study and the program sessions (time, duration, place, and contents). The researcher stressed on the importance of continuous attendance and active participation. Different teaching and learning methods were used during the sessions which included; interactive lecture, group discussion, demonstration \& re-demonstration, instructional media included data show \& lab models and printed handout.

\section{Evaluation Phase}

The effectiveness of the program was evaluated by two tests; the first post- test was done immediately by the end of the program, the second post test was done three months later after program implementation using the same tool which was used in the pre- test.

\section{Results}

Table (1) shows that the age of the study group ranged from 18- 60 years with a mean age 39.07 \pm 12.63 years and two-fifths $(40.0 \%)$ of them were between the ages of $46-60$ years. Concerning marital status, it was found that the highest percentages $(59.3 \%)$ of the study group were married and the lowest percentages $(2.8 \%)$ were divorced. Regarding to level of education, it was observed that slightly less than two-thirds $(63.9 \%)$ of the study group had a technical secondary education, while $2.8 \%$ of them only had a general secondary education. In relation to crowding index, the table revealed that the mean crowding index was $1.58 \pm 0.56$. Eventually, the table explained that slightly more than two-thirds $(66.7 \%)$ of the study group reported that each hadn't enough income.

Table (2) demonstrats that less than half $(46.3 \%)$ of the study group are working morning shifts, slightly more than one-fifth $(21.3 \%)$ have been working more than one shift, and slightly less than one-third (32.4\%) are working on afternoon shifts. The results also revealed that the working hours of the study group are ranged between 6 -12 hours per day with a median of eight hours, more than half $(52.8 \%)$ are working less or equal to eight hours per day, while those who work more than eight hours per day represented $47.2 \%$. In relation to years of experience, half $(50.0 \%)$ of the study group reported having experience more than 10 years, while only $7.4 \%$ of the study group reported having experience less than or equal one year. As regards to position of the study group during working, less than half $(46.3 \%)$ of them are working in a standing position, while those who work in a sitting and bending positions are $39.8 \%$ and $13.9 \%$, respectively (as they reported).

Table (3) illustrates distribution of the study group according to their total mean score of knowledge \& attitude and practice throughout the educational program. As evident in the table there was significant improvement in the study group's total knowledge mean score $47.74 \pm 3.92$, total attitude mean score $138.58 \pm 5.99$ and total practice mean score $12.82 \pm 1.55$ throughout the program. The scores were highest in posttest and decline slightly in the follow- up phases to reach $41.49 \pm 5.44$ for total knowledge mean score, $129.31 \pm 7.84$ for total attitude mean score, and $11.17 \pm 2.08$ for total practice mean score. Nonetheless, both posttest and follow-up test had shown higher improvement compared to the pre- test.There were statistically significant differences between the study group's total knowledge mean score, total attitude mean score and total practice mean score before and after implementation of the educational program at $\mathrm{p}<0.001$. 
Table (4) displays percent changes in total scores of knowledge, attitude and practice of the study group throughout the educational program. As transpired in the table, the highest percentages of change were in knowledge, reaching $73.20 \pm 26.10$ with a median of 73.08 between posttest and pre -program level followed by percentages of attitude which reached $59.88 \pm 13.63$ with a median58.92 between posttest and pre -program level. Conversely, the lowest percentages of change were in practice, especially between posttest and pre-program level $-23.25 \pm 4.31$ with a median of -23.92 .

Table (5) puzzles out the relation between total knowledge of the study group and their sociodemographic data throughout the educational program. As exhibited in the table, there was a statistical significant association between the educational level of the study group and their total knowledge score throughout the three levels of the educational program at $\mathrm{p}<0.001^{*}$. No other statistically significant association could be detected in this table.

Table (6) submitts the relation between total attitude of the study group with their socio- demographic data and work characteristics throughout the educational program. As described in the table, there was no statistical significant association between age, marital status, education, years of experience, monthly income, nor working hours with a total attitude score of the study group.

Table (7) exhibits the relation between total practice of the study group with their socio- demographic data and work characteristics throughout the educational program. As viewed in the table, there was a statistically significant association between level of education of the study group and their total practice score at pretest phase where $\mathrm{p}=0.003^{*}$ and at follow-up phase where $\mathrm{p}=0.002^{*}$. The table also shows that there was a statistically significant association between years of experience of the study group and their total practice at pretest phase where $\mathrm{p}=0.020^{*}$. No other statistically significant association could be detected in this table.

Table (1): Distribution of the study group according to their socio demographic data $(\mathrm{n}=108)$

\begin{tabular}{|c|c|c|}
\hline & No. & $\%$ \\
\hline \multicolumn{3}{|l|}{ Age (years) } \\
\hline$\leq 30$ & 32 & 29.6 \\
\hline $31-45$ & 33 & 30.4 \\
\hline $46-60$ & 43 & 40.0 \\
\hline Min. - Max. & \multicolumn{2}{|c|}{$18.0-60.0$} \\
\hline Mean \pm SD & \multicolumn{2}{|c|}{$39.07 \pm 12.63$} \\
\hline Median & \multicolumn{2}{|c|}{38.0} \\
\hline \multicolumn{3}{|l|}{ Marital status } \\
\hline Single & 24 & 22.2 \\
\hline Married & 64 & 59.3 \\
\hline Divorced & 3 & 2.8 \\
\hline Widowed & 17 & 15.8 \\
\hline \multicolumn{3}{|l|}{ Education } \\
\hline cannot read \& write & 10 & 9.3 \\
\hline Read and write & 13 & 12.0 \\
\hline Secondary education & 7 & 6.5 \\
\hline Basic education & 3 & 2.8 \\
\hline Technical secondary education & 69 & 63.9 \\
\hline University education & 6 & 5.6 \\
\hline \multicolumn{3}{|l|}{ Crowding index } \\
\hline Range. & \multicolumn{2}{|c|}{$0.33-3.0$} \\
\hline Mean \pm SD & \multicolumn{2}{|c|}{$1.58 \pm 0.56$} \\
\hline Median & \multicolumn{2}{|c|}{1.67} \\
\hline \multicolumn{3}{|l|}{ Monthly income } \\
\hline Not enough & 72 & 66.7 \\
\hline Enough & 36 & 33.3 \\
\hline Enough and more & - & - \\
\hline
\end{tabular}

Table (2): Distribution of the study group according to their work characteristics $(\mathrm{n}=108)$

\begin{tabular}{|l|c|c|}
\hline & No. & $\%$ \\
\hline Work Shifts & & \\
\hline Morning & 50 & 46.3 \\
\hline Afternoon & 35 & 32.4 \\
\hline More than one shift & 23 & 21.3 \\
\hline Working Hours / Day & & \\
\hline More than 8 hours & 57 & 52.8 \\
\hline Less than 8 hours & 51 & 47.2 \\
\hline Min. - Max. & \multicolumn{2}{|c|}{$6.0-12.0$} \\
\hline Mean \pm SD. & \multicolumn{2}{|c|}{$8.0 \pm 2.56$} \\
\hline Median & \multicolumn{2}{|}{} \\
\hline $\begin{array}{l}\text { Working duration } \\
\text { (years of experience) }\end{array}$ & & \\
\hline
\end{tabular}




\begin{tabular}{|l|c|c|}
\hline$\leq 1$ & 8 & 7.4 \\
\hline $2-\leq 5$ & 20 & 18.5 \\
\hline $6-\leq 10$ & 26 & 24.1 \\
\hline$>10$ & 54 & 50.0 \\
\hline & \multicolumn{2}{|c|}{$1.0-37.0$} \\
\hline Mean \pm SD. Min. - Max. & \multicolumn{2}{|c|}{$14.05 \pm 10.73$} \\
\hline Median & \multicolumn{2}{|c|}{} \\
\hline Position during Work & 43 & 39.8 \\
\hline Sitting & 50 & 46.3 \\
\hline Standing & 15 & 13.9 \\
\hline Bending for long periods & \multicolumn{2}{|c|}{} \\
\hline
\end{tabular}

Table (3):Distribution of the study group according to their total score of knowledge \& attitude and practice throughout the educational program $(\mathrm{n}=108)$.

\begin{tabular}{|c|c|c|c|c|c|c|c|c|}
\hline & \multicolumn{2}{|c|}{$\begin{array}{c}\text { Pretest } \\
(n=108)\end{array}$} & \multicolumn{2}{|c|}{$\begin{array}{l}\text { Posttest } \\
(n=108)\end{array}$} & \multicolumn{2}{|c|}{$\begin{array}{c}\text { Follow-up } \\
(n=108)\end{array}$} & \multirow[t]{2}{*}{$\mathrm{F} \square^{2}$} & \multirow[t]{2}{*}{$\mathbf{p}$} \\
\hline & No. & $\%$ & No. & $\%$ & No. & $\%$ & & \\
\hline \multicolumn{9}{|c|}{ Total knowledge score } \\
\hline$<50$ Poor & 100 & 92.6 & 1 & 0.9 & 10 & 9.3 & \multirow[t]{3}{*}{$186.928^{*}$} & \multirow[t]{3}{*}{$<0.001^{*}$} \\
\hline $50-<75$ Average & 7 & 6.9 & 16 & 14.8 & 75 & 69.4 & & \\
\hline$\geq 75 \mathrm{Good}$ & 1 & 0.9 & 91 & 84.3 & 23 & 21.3 & & \\
\hline Min. - Max. & \multicolumn{2}{|c|}{$19.0-52.0$} & \multicolumn{2}{|c|}{$35.0-54.0$} & \multicolumn{2}{|c|}{$28.0-69.0$} & \multirow{2}{*}{$\begin{array}{c}\mathrm{F}= \\
842.665^{*}\end{array}$} & \multirow[t]{2}{*}{$<0.001^{*}$} \\
\hline Mean \pm SD. & \multicolumn{2}{|c|}{$28.20 \pm 5.05$} & \multicolumn{2}{|c|}{$47.74 \pm 3.92$} & \multicolumn{2}{|c|}{$41.49 \pm 5.44$} & & \\
\hline \multicolumn{9}{|l|}{ Total attitude } \\
\hline$<60$ Negative & 108 & 100.0 & 0 & 0.0 & 2 & 1.9 & \multirow[t]{2}{*}{$212.074^{*}$} & \multirow[t]{2}{*}{$<0.001^{*}$} \\
\hline$\geq 60$ Positive & 0 & 0.0 & 108 & 100.0 & 106 & 98.1 & & \\
\hline Min. - Max. & \multicolumn{2}{|c|}{$71.0-107.0$} & \multicolumn{2}{|c|}{$124.0-150.0$} & \multicolumn{2}{|c|}{$115.0-178.0$} & \multirow{2}{*}{$\begin{array}{c}\mathrm{F}= \\
1744.74^{*}\end{array}$} & \multirow[t]{2}{*}{$<0.001^{*}$} \\
\hline Mean \pm SD. & \multicolumn{2}{|c|}{$87.16 \pm 6.61$} & \multicolumn{2}{|c|}{$138.58 \pm 5.99$} & \multicolumn{2}{|c|}{$129.31 \pm 7.84$} & & \\
\hline \multicolumn{9}{|l|}{ Total practice score } \\
\hline$<50$ Poor & 97 & 89.8 & 3 & 2.8 & 26 & 24.1 & \multirow[t]{3}{*}{$164.843^{*}$} & \multirow[t]{3}{*}{$<0.001^{*}$} \\
\hline $50-<75$ Average & 11 & 10.2 & 37 & 34.3 & 49 & 45.4 & & \\
\hline$\geq 75 \mathrm{Good}$ & 0 & 0.0 & 68 & 63.0 & 33 & 30.6 & & \\
\hline Min. - Max. & \multicolumn{2}{|c|}{$5.0-12.0$} & \multicolumn{2}{|c|}{$\frac{1}{9.0-15.0}$} & \multicolumn{2}{|c|}{$6.0-15.0$} & \multirow{2}{*}{$\begin{array}{c}\mathrm{F}= \\
426.728^{*}\end{array}$} & \multirow[t]{2}{*}{$<0.001^{*}$} \\
\hline Mean \pm SD. & 7.5 & 1.57 & 12.8 & 1.55 & 11. & 2.08 & & \\
\hline
\end{tabular}

$\chi^{2}$ : Chi square test for Friedman test

F: F test (ANOVA)

*: Statistically significant at $\mathrm{p} \leq 0.05$

Table (4): Percent changes in total scores of knowledge, attitude and practice of the study group throughout the educational program.

\begin{tabular}{|l|c|c|c|}
\hline \multicolumn{1}{|c|}{ Change in score \% } & Min. - Max. & Mean \pm SD. & Median \\
\hline Knowledge & & & 73.08 \\
\hline Post-pre & $0.0-145.0$ & $73.20 \pm 26.10$ & 47.91 \\
\hline Fu-pre & $-25.0-109$. & $49.81 \pm 22.41$ & \\
\hline Attitude & & & 58.92 \\
\hline Post-pre & $23.08-100.0$ & $59.88 \pm 13.63$ & 48.86 \\
\hline Fu-pre & $14.95-106.98$ & $49.20 \pm 14.27$ & \\
\hline Practice & & & -23.92 \\
\hline Post-pre & $-31.47--9.91$ & $-23.25 \pm 4.31$ & -17.74 \\
\hline Fu-pre & $-29.50--4.46$ & $-17.54 \pm 4.89$ & \\
\hline
\end{tabular}

Table (5): Relation between total knowledge of the study group with their socio- demographic data and work charactarestics throughout the educational program

\begin{tabular}{|l|c|c|c|}
\hline & \multicolumn{3}{|c|}{ Knowledge } \\
\hline Age (years) & Pretest & Posttest & Follow- up \\
\hline$\leq 30$ & & & $42.06 \pm 4.37$ \\
\hline $31-45$ & $27.56 \pm 4.30$ & $48.66 \pm 2.62$ & $41.09 \pm 5.33$ \\
\hline $46-60 \quad$ F (p) & $29.09 \pm 5.02$ & $47.76 \pm 4.85$ & $41.37 \pm 6.26$ \\
\hline \multicolumn{1}{|c|}{$28.0 \pm 5.58$} & $47.05 \pm 3.87$ & $0.273(0.762)$ \\
\hline Marital status & $0.800(0.452)$ & $1.565(0.214)$ & \\
\hline Single & & & $41.25 \pm 3.61$ \\
\hline Married & $26.33 \pm 3.25$ & $47.88 \pm 2.44$ & $41.80 \pm 6.21$ \\
\hline
\end{tabular}




\begin{tabular}{|c|c|c|c|}
\hline Divorced & $28.0 \pm 4.58$ & $48.33 \pm 5.03$ & $42.67 \pm 3.21$ \\
\hline Widowed & $55.25 \pm 7.17$ & $95.38 \pm 4.19$ & $81.44 \pm 5.03$ \\
\hline $\mathbf{F}(\mathbf{p})$ & $1.200(0.315)$ & $0.058(0.994)$ & $0.243(0.913)$ \\
\hline \multicolumn{4}{|l|}{ Education } \\
\hline cannot read \& write & $25.90 \pm 4.48$ & $43.20 \pm 4.26$ & $36.0 \pm 5.10$ \\
\hline Read and write & $27.38 \pm 3.62$ & $47.62 \pm 2.96$ & $42.38 \pm 8.59$ \\
\hline Secondary education & $33.14 \pm 9.25$ & $49.43 \pm 2.76$ & $42.71 \pm 5.09$ \\
\hline Basic education & $25.33 \pm 7.77$ & $46.0 \pm 5.20$ & $38.33 \pm 8.96$ \\
\hline $\begin{array}{l}\text { Technical secondary } \\
\text { education }\end{array}$ & $27.61 \pm 3.86$ & $47.84 \pm 3.53$ & $41.39 \pm 3.69$ \\
\hline University education & $36.33 \pm 3.61$ & $53.33 \pm 0.82$ & $50.0 \pm 1.67$ \\
\hline $\mathbf{F}(\mathbf{p})$ & $6.752^{*}\left(<0.001^{*}\right)$ & $7.092^{*}\left(<0.001^{*}\right)$ & $6.767^{*}\left(<0.001^{*}\right)$ \\
\hline \multicolumn{4}{|c|}{$\begin{array}{l}\text { Working duration(years } \\
\text { of experience) }\end{array}$} \\
\hline$\leq 1$ & $26.62 \pm 2.88$ & $47.75 \pm 1.98$ & $41.0 \pm 3.55$ \\
\hline $2-\leq 5$ & $29.20 \pm 4.92$ & $49.55 \pm 3.12$ & $43.75 \pm 4.72$ \\
\hline $6-\leq 10$ & $28.81 \pm 5.25$ & $48.04 \pm 3.77$ & $40.85 \pm 4.56$ \\
\hline$>10$ & $27.78 \pm 5.25$ & $46.93 \pm 4.28$ & $41.04 \pm 6.15$ \\
\hline $\mathbf{F}(\mathbf{p})$ & $0.767(0.515)$ & $2.334(0.078)$ & $1.438(0.236)$ \\
\hline \multicolumn{4}{|l|}{ Monthly income } \\
\hline Not enough & $27.95 \pm 4.49$ & $47.0 \pm 4.51$ & $40.33 \pm 5.26$ \\
\hline Enough & $28.35 \pm 5.37$ & $48.18 \pm 3.49$ & $42.18 \pm 5.46$ \\
\hline$t(p)$ & $0.399(0.691)$ & $1.516(0.133)$ & $1.725(0.087)$ \\
\hline \multicolumn{4}{|l|}{ Working Hours / Day } \\
\hline More than 8 hours & $27.78 \pm 4.81$ & $47.51 \pm 3.99$ & $41.29 \pm 5.82$ \\
\hline Less than 8 hours & $29.26 \pm 5.54$ & $48.32 \pm 3.73$ & $42.0 \pm 4.37$ \\
\hline t (p) & $1.383(0.170)$ & $0.979(0.330)$ & $0.616(0.539)$ \\
\hline
\end{tabular}

F: F test (ANOVA)

$\mathrm{t}$ : Student t-test

*: Statistically significant at $\mathrm{p} \leq 0.05$.

Table (6): Relation between total attitude of the study group with their socio- demographic data and work charactarestics throughout the educational program

\begin{tabular}{|c|c|c|c|}
\hline & \multicolumn{3}{|c|}{ Attitude } \\
\hline & Pretest & Posttest & Follow-up \\
\hline \multicolumn{4}{|l|}{ Age (years) } \\
\hline$\leq 30$ & $87.22 \pm 6.33$ & $138.28 \pm 5.94$ & $128.75 \pm 4.98$ \\
\hline $31-45$ & $87.525 \pm 7.51$ & $138.94 \pm 6.77$ & $129.94 \pm 9.14$ \\
\hline $46-60$ & $86.84 \pm 6.21$ & $138.53 \pm 5.51$ & $129.26 \pm 8.61$ \\
\hline $\mathbf{F}(\mathbf{p})$ & $0.098(0.906)$ & $0.099(0.906)$ & $0.186(0.830)$ \\
\hline \multicolumn{4}{|l|}{ Marital status } \\
\hline Single & $87.58 \pm 5.97$ & $138.21 \pm 5.79$ & $128.79 \pm 5.38$ \\
\hline Married & $87.02 \pm 6.70$ & $138.50 \pm 6.0$ & $129.73 \pm 9.26$ \\
\hline Divorced & $89.0 \pm 5.00$ & $139.67 \pm 11.158$ & $124.0 \pm 5.57$ \\
\hline Widowed & $86.76 \pm 7.74$ & $139.24 \pm 5.80$ & $129.41 \pm 4.65$ \\
\hline $\mathbf{F}(\mathbf{p})$ & $0.137(0.937)$ & $0.132(0.941)$ & $0.550(0.649)$ \\
\hline \multicolumn{4}{|l|}{ Education } \\
\hline Cannot read \& write & $90.40 \pm 6.55$ & $140.0 \pm 6.99$ & $135.20 \pm 15.64$ \\
\hline Read and write & $87.08 \pm 4.55$ & $139.15 \pm 4.32$ & $128.92 \pm 4.96$ \\
\hline Secondary education & $83.86 \pm 7.17$ & $137.29 \pm 5.91$ & $128.43 \pm 5.26$ \\
\hline Basic education & $84.0 \pm 3.0$ & $135.33 \pm 7.37$ & $124.67 \pm 5.13$ \\
\hline Technical secondary education & $86.97 \pm 7.0$ & $138.70 \pm 6.28$ & $129.03 \pm 7.02$ \\
\hline University education & $89.50 \pm 5.24$ & $136.83 \pm 4.36$ & $127.0 \pm 3.22$ \\
\hline $\mathbf{F}(\mathbf{p})$ & $1.137(0.346)$ & $0.473(0.796)$ & $1.522(0.190)$ \\
\hline \multicolumn{4}{|l|}{$\begin{array}{l}\text { Working duration(years of } \\
\text { experience) }\end{array}$} \\
\hline$\leq 1$ & $89.38 \pm 5.68$ & $139.63 \pm 4.98$ & $129.0 \pm 4.14$ \\
\hline $2-\leq 5$ & $88.60 \pm 7.32$ & $138.15 \pm 5.59$ & $128.60 \pm 5.0$ \\
\hline $6-\leq 10$ & $87.31 \pm 6.27$ & $136.77 \pm 6.89$ & $128.27 \pm 5.79$ \\
\hline$>10$ & $86.22 \pm 6.62$ & $139.46 \pm 5.64$ & $130.13 \pm 9.78$ \\
\hline $\mathbf{F}(\mathbf{p})$ & $0.982(0.404)$ & $1.309(0.276)$ & $0.402(0.752)$ \\
\hline \multicolumn{4}{|l|}{ Monthly income } \\
\hline Not enough & $87.13 \pm 6.25$ & $137.86 \pm 6.27$ & $129.54 \pm 9.15$ \\
\hline Enough & $87.22 \pm 7.36$ & $140.03 \pm 5.18$ & $128.86 \pm 4.20$ \\
\hline $\mathbf{t}(\mathbf{p})$ & $0.072(0.943)$ & $1.789(0.076)$ & $0.424(0.673)$ \\
\hline \multicolumn{4}{|l|}{ Working Hours / Day } \\
\hline More than 8 hours & $87.58 \pm 6.75$ & $138.62 \pm 6.12$ & $129.57 \pm 8.70$ \\
\hline Less than 8 hours & $86.10 \pm 6.23$ & $138.48 \pm 5.77$ & $128.68 \pm 5.20$ \\
\hline$t(p)$ & $1.059(0.292)$ & $0.109(0.913)$ & $0.534(0.594)$ \\
\hline
\end{tabular}




\section{F: F test (ANOVA)}

t: Student t-test

*: Statistically significant at $\mathrm{p} \leq 0.05$

Table (7): Relation between total practice of the study group with their socio- demographic data and work charactarestics throughout the educational program

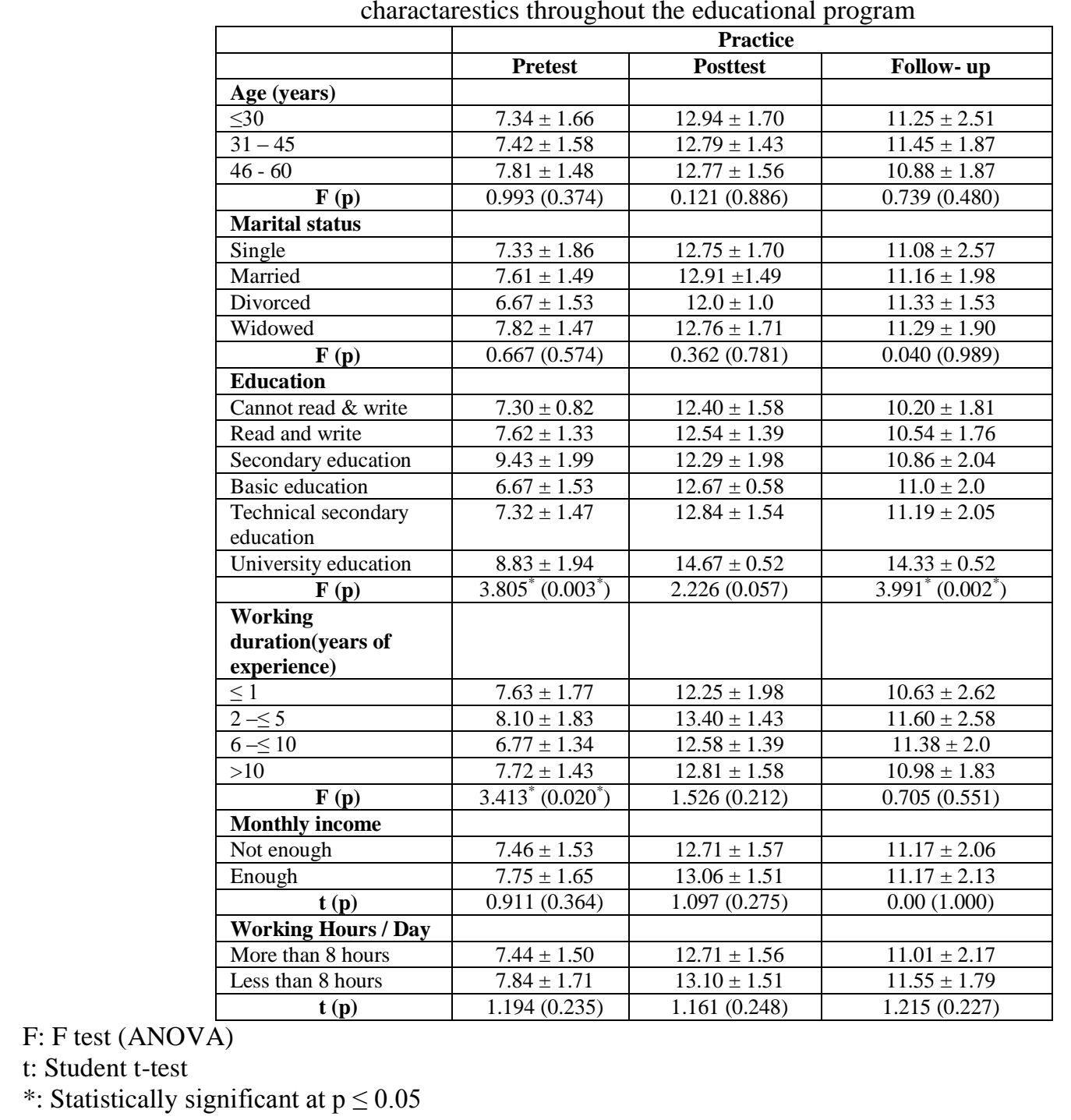

\section{Discussion:}

The primary aim of any occupational health and safety program is the prevention of accidents and illness, which employs knowledge as the principal tool. Only accurate knowledge of the risks and adequate training in handling them can enable the worker to adopt appropriate behavior in a hazardous working environment. A successful accident prevention program depends on leadership by the employer and safe work habits and practices by the employees (Magoro, 2012). Therefore, the main concern of the current study is to evaluate the effect of an educational program about occupational health and safety on knowledge, attitude, and practice of workers in textile factory in Damietta City.

The findings of current study, showed that the age of the study group ranged from 18- 60 years with a mean age 39.07 \pm 12.63 years and two-fifths of them were between the ages of $46-60$ years, the highest were married and the lowest percentages were divorced, slightly less than two-thirds had a technical secondary education and slightly more than two-thirds of the study group reported that each hadn't enough income.

Concerning knowledge, attitude, and practice of the study group in relation to Occupational Health and Safety before implementation of the educational program, the findings of the present study reflected that the majority of the study group had poor total knowledge, negative attitude, as well as poor reported practice. This may be due to the limited access of information and there were no regular and periodic educational sessions about occupational hazards and Occupational Health and Safety offered to them. In addition, there was a 
remarkable lack of clear policy, lack of investment and interest in occupational health and safety issues and a shortage of preventive strategies, implemented by the factory managers and Occupational Health and Safety supervisors which probably resulted in that significant decline in knowledge, attitude, and practice before implementation of the program.

This finding is supported by Tetemke et al., 2014, reported that the practice towards safety information is inadequate. In addition, found that the workers have less knowledge level compared to other studies although they have fair practices on safety measures or personal protective device usages. Moreover, Nasab et al., (2009, depicted that knowledge, attitude and safe behaviors of the workers are unacceptable, so they suggested and concluded that managers should design and implement educational interventions to promote knowledge, attitude and safe behaviors of workers.

Furthermore, Dhawan, et al., (2015), indicated a lack of knowledge and casual attitude of the dyers making them prone to health hazards linked to chemical dyes. Also, Norkaew, (2010), elaborated that the majority of chili-growing farmers have low knowledge, negative attitude and fair practices. On the other hand, Khoso and Nafees, (2015), stated that, there was no significant association of knowledge, attitude and practices with respiratory symptoms. In addition, Paramasivam, et al., (2010), indicated that the workers have knowledge regarding the occupational hazards and their attitudinal approach toward the betterment of the work environment is positive

On examining the effect of the implemented educational program on the study group's total knowledge, attitude and practice scores. It was found that there was a highly statistically significant improvement in their total level of knowledge, attitude and practice in post- and follow- up test. This remarkable and obvious improvement could be attributed to the effect of the implemented program, which included all information and skills required for the study group to be healthy and helping them to avoid the occurrence of higher levels of occupational hazards at the workplace and to the fact that it was custom-tailored to workers' needs. These findings strongly support the hypotheses "that the level of workers' knowledge, attitude, and practice will be improved after implementation of the program".

By the same token, there was a slight decrease in the percentages of total knowledge, attitude and practice scores at follow-up phase than immediate posttest phase and it possibly might be due to forgetting because of the period that may be fairly long between the two tests (three months), and such deterioration highlighted the need to repeat the program every three to six months. Also, results revealed that there were highly statistically significant differences between all values during the three phases of the educational program.

The aforementioned findings are in agreement with, Abd EL Hameed et al, (2012), who demonstrated that the mean scores of knowledge regarding the direct effects of cotton dust on workers' health, control of cotton dust and the protective equipment are highly significant differences before and after the educational intervention, they also mentioned that there are statistical significant difference of the workers' compliance with the usage of personal protective equipment (coverall, head cover, safety shoes/boots, face/nose masks and safety gloves) which reflects the raising of workers' awareness after the educational intervention. Moreover, the study clarified that there is a statistical significant difference before and after the educational intervention for all personal protective equipment except the using of ear plugs.

Also, Milczarek and Szczecińska, (2006), concluded that there are changes in work organization and improvement in the way workstations are looked after, which led to a decrease in occupational risk also mentioned that level of knowledge of workers is improved significantly after implementing the educational and training courses. Furthermore, Padmini and Venmathi, (2013), accentuated that there is a significant improvement in the knowledge of the workers after the awareness program. Moreover, Sayapathi et al., (2014), found that, the mean scores of knowledge, belief and practice constructs have increased over a period of six months from pre-intervention. This shows that the levels of knowledge, belief and practice have increased similarly among participants from the two factories over six months.Regarding relationship between sociodemographic data and work characteristics of the study group with their total knowledge scores. The findings of the current study exhibited that, there was a statistical significant association between educational level of the study group and their total knowledge score throughout the three levels of the educational program while there was no other statistically significant association between total knowledge of the study group and other sociodemographic data. This finding strongly supported the study hypothesis that, "there will be a statistically significant association between level of education of the workers and their total knowledge scores". This can partly be explained by the fact that educated workers have better access to Occupational Health and Safety information, improved perceptions towards occupational hazards, and can utilize health care service information optimally. This finding is in agreement with Khoso and Nafees (2015), who reported that education is significantly associated with good knowledge and appropriate attitude. While, Malik et al., (2010), confirmed that there is a strong association between age of the workers and occupational health and safety knowledge.

Concerning the relationship between socio-demographic data and work characteristics of the study group with their total attitude score, the finding of the present study depicted that there was no statistical 
significant association between age, marital status, education, years of experience, monthly income, nor working hours with total attitude scores of the studied group. These results are inconsistent with the research hypothesis, which was supposed a statistical significant association between level of education of the study group and their total attitude.

These findings are in contrast with Nasab et al., (2009), who found that there is a statistically significant association between age of workers and their total attitude, also, revealed that there is statistically significant association between years of experience of the workers with their total attitude. Furthermore, Kebede, (2014), clarified that there is a statistically significant association between level of education of workers and their total attitude, also, revealed that there is a statistically significant association between years of experience of the workers with their total attitude.

In respect to the relation between socio-demographic data and work characteristics of the study group with their total practices, the current study elaborated that there was statistically significant association between level of education of the study group and their total practice scores, also, data showed that there was statistically significant association between years of experience of the study group with their total practice. This finding strongly supports the research hypothesis that" there will be statistically significant association between level of education of the workers and their total practice scores ". This might be explained that, educated \& working persons may have a higher level of awareness about proper practices and have better access to health service information, improved perceptions towards occupational health and safety and can utilize health care service information optimally. These findings are in agreement with Tetemke, et al., (2014), who revealed that variables such as gender, education level, employment pattern, working section, having safety training, work regulation and knowledge regarding safety information have significant association with PPE use. Furthermore, Adebola (2014), reported that there is a statistical significant relationship between Educational Status and Practice at the $95 \%$ level of significance $\mathrm{p}<0.05$.

\section{Conclusion}

Almost all of the study group had poor total knowledge, negative attitude as well as poor total practice regarding Occupational Health and Safety before application of the health educational program. After implementation of the health educational program a remarkable improvement was detected with highly statistical significant differences during pre-, post- and follow-up phases. Therefore, the educational program was successful in attaining its aim of positively changing kneledge, attitude and practice practices and of the studied group regarding occupational health and safety

\section{Recommendations}

1- Provision of special teaching classes supplied with T.V, video and training aids to educate and train workers about everything related to Occupational Health and Safety through pre- declared agenda containing times and dates suitable for workers. Teaching and training programs should be based on workers' needs, characteristcs and abilities.

2- Stressing on the application of the International Standards of Occupational Health and Safety in field of work to improve their performance.

3- Periodic check up for workers for early detection of occupational hazards to monitor the health status and early case finding.

4- Replication of similar specific studies using large probability samples and different settings ( including governmental and non governmental textile factories) is highly recommended.

\section{References}

[1]. Abd EL-Hameed, H., Aly, H., \&Abd El-Latif O. (2012). An intervention study to evaluate compliance with personal protective equipment among workers at Textile industry. Journal of American Science; 8 (7): 117-121. (ISSN: 1545-1003). Available at: http:// www.jofamericanscience.org.

[2]. Adebola, J . (2014). Knowledge, Attitude and Compliance with Occupational Health and Safety Practices among Pipeline Products and Marketing Company (PPMC) Staff in Lagos. Merit Research Journal of Medicine and Medical Sciences; 2(8): 158-173. ISSN: 2354-3238.

[3]. Babel, S., \& Tiwari, M. (2014).Occupational health hazards in textiles industry. Asian Journal of Home Science (AJHS); 9(1): 267271.

[4]. Coope,r K., \& Gosnell, K. ( 2015).Foundations and Adult Health Nursing. $7^{\text {th }}$ ed., Canada: Elsevier Health Sciences; p 2055. ISBN: 0323293131,9780323293136 .

[5]. Dhawan, G., Gupta, S., Dhawan, U., \& et al.( 2015). An Explorative Study on Knowledge and Awareness of Health Problems Related to Usage of Fabric Dyes by Road Side Dyers in Delhi, India . DU Journal of Undergraduate Research and Innovation;1(3):20-25.

[6]. Estes, M.(2014). Health Assessment and Physical Examination. $5^{\text {th }}$ ed., U.S.A: Cengage Learning; p 1069. ISBN: 1133610935, 9781133610939 .

[7]. Friend, M.\& Kohn, J. (2010). Fundamentals of occupational safety and health. $5^{\text {th }}$ ed., U.S.A: Government Institute an imprint of the scarecrow Press, Inc; p. 177. ISBN: 1605907073, 9781605907079. 
[8]. Friend, M.\& Kohn, J. (2014). Fundamentals of Occupational Safety and Health.6 $6^{\text {th }}$ ed., U.S.A: Bernan Press; p p. 2-3. ISBN: $1598887246,9781598887242$.

[9]. Guidotti, T. (2011).Global Occupational Health. $1^{\text {st }}$ ed., New York, U.S.A: Oxford University Press; p p. 3-5 \& 15-16 .ISBN 978-019-538000-2.

[10]. Guidotti, T., Arnold, M.\& Lukcso, D. (2013). Occupational Health Services: A practical approach. $2^{\text {nd }}$ ed., New York 10017, U.S.A: Routledge; p p. 276-278.

[11]. Guzys, D., \&Petrie, E. (2014). An Introduction to Community and Primary Health Care. $1^{\text {st }}$ ed., U.S.A: Cambridge University Press; p.323. ISBN: 1107513529,9781107513525 .

[12]. Haggag, M. (1995).The Impact of Child's Labor on His Health Status in Alexandria, Doctoral Thesis, Faculty of Nursing, Alexandria University.

[13]. Ibrahim, A. (2014). Relationship between Occupational Health Hazards and the Use of Safety Measures among Workers in Textile Factory in Port Said City. Un Published Master Thesis. Faculty of nursing, Port Said University.

[14]. Kebede,M. (2014).Assessment of Knowelsdge, attitude\& practice towards safety measures among workers in fdre metal Engineering Corporation/ Metec/. A thesis submiteed to the department emergency medicine, school of medicine, Addis Ababa University in partial fulfillment of. The requirements for the degree of master of emergency medicine \& critical care .

[15]. Khan, A., Moshammer, H., \& Kundi, M. (2015). Industrial hygiene, occupational safety and respiratory symptoms in the Pakistani cotton industry. BMJ Open; 5(4): 1-8. Doi: 10.1136/bmjopen-2014-007266.

[16]. Khoso, A., \& Nafees, A. (2015). Knowledge, attitude and practices regarding respiratory symptoms among textile workers of Karachi, Pakistan: a cross-sectional survey. J Pak Med Assoc.;65(1):17-23.

[17]. Kumar, C., Sakthivel, M., Elangovan, R., \& et al. (2015). Analysis of Material Handling Safety in Construction Sites and Countermeasures for Effective Enhancement. The Scientific World Journal; 2015(2015):1-7. http://dx.doi.org/10.1155/2015/742084

[18]. Kun, A. (2014). Work accident compensation in Hungarian labour law - liability rules and compensation: Hungarian Labor law -EJournal. Károli Gáspár University of the Reformed Church in Hungary (Budapest), Faculty of Law, Department of Labour Law and Social Security; P p 64. Adopted from WHO(2010): Healthy Workplace Framework and Model: Background and Supporting Literature and Practices, Joan Burton (ed.), WHO Headquarters, Geneva, Switzerland, p. 7.

[19]. Magoro, F. (2012). Knowledge, Attitude and Practices Regarding Personal Protective Equipment Amongst Stevens Lumber Mills employees in the Capricorn district of Limpopo Province, South Africa. A mini dissertation submitted in partial fulfillment of the requirements for the degree of master of public, in the school of Health Science, Faculty of Health Science, University of Limpopo.P8

[20]. Malik, N., Maan, A., Pasha, T., et al. (2010). Role of Hazard Control Measures In occupational health and Safety in the Textile Industry of Pakistan. Pak .J. Agri. Sci; Vol 47 (1): 72-76. Available at: http://www.pakjas.cpm.pk.

[21]. McCullagh, M., \& Berry , P. (2015). A Safe and Healthful Work Environment: Development and Testing of an Undergraduate Occupational Health Nursing Curriculum. Workplace Health Saf; 63(8): 328-332. doi:10.1177/2165079915584127.

[22]. Milczarek, M., \& Szczeci $\square$ ska K.(2006).Workers' active involvement in the improvement of occupational safety and health in a textile enterprise--a case study. Int J Occup Saf Ergon;12(1):69-77.

[23]. Miller, R. (2012). Epidemiology for Health Promotion and Disease Prevention Professionals. $2^{\text {nd }}$ ed., New York 10017: Routledge. p 302.

[24]. Motbainor, A., Kumie, A., \& Melkamu, Y. (2007). Assessment of Knowledge and practice on safety information among factory workers. a thesis submitted to the school of graduate studies of addis ababa university in partial fulfillment of the requirement for the degree of master in public health, Addis Ababa, Ethiopia.

[25]. Nasab, H., Tavakoli, R., \& Ghofranipour, F. (2009). Evaluation of Knowledge, Attitude and Behavior of Workers towards Occupational Health and Safety. Iranian Journal of Public Health. 38(2):125-129.

[26]. Nickitas, M., Middaugh, D., \& Aries, N. (2011). Policy and Politics for nurses and other health professional. New York, U.S.A: Jones and Bartlett publishers. LLC; P. 40.

[27]. Nies, M.\& McEwen, M. (2015).Community/Public Health Nursing - Elsevieron VitalSource: Promoting the Health of Populations. $6^{\text {th }}$ ed., Canada: Elsevier Health Sciences; p p. 602-607. ISBN: 0323293875, 9780323293877.

[28]. Norkaew, S., Siriwong, W., Siripattanakul, S., \& et al.(2010). Knowledge, Attitude, and Practice (KAP) of using Personal Protective Equipment (PPE) for chill growing farmers in Hua Rua sub-district, Muang district, Ubonratchathani Province, Thailand. J Health Res ; 24 (2): 93- 100.

[29]. Padmini, D., \& Venmathi, A. (2013). Creating Awareness on Occupational Health and Safety among Workers Employed in Garment Industries. Ijsr - International Journal of Scientific Research; 2 (12 ).275-277. ISSN No $2277-8179$.

[30]. Paramasivam, P., Raghavan, P., Srinivasan, P., \& et al. (2010). Knowledge, attitude, and practice of dyeing and printing workers. Indian J Community Med. 35(4):498-501. doi: 10.4103/0970-0218.74358.

[31]. Sayapathi, B., Su, A., \& Koh, D. (2014). Knowledge, Attitudes and Practice in Relation to Noise-Induced Hearing Loss in Two Factories, Malaysia.Research Journal of Biological Sciences.9(6): 197-204.ISSN: 1815-8846.

[32]. Shafik, S., \&Abd-El Mohsen, A. (2012).Occupational health: Health promotion program to Improve Health Workers in Tourah Cement Factory .Journal of American Science; 8(3):486-496.

[33]. Tetemke, D., Alemu, K., Tefera, Y., \& et al. (2014). Knowledge and practices regarding safety information among textile workers in Adwa town, Ethiopia. Science Postprint1(1): 1-5.e00015. doi:10.14340/spp.2014.01 A0004.

[34]. Tunsaringkarn, S., Siriwong, W., Sematong, S., et al. ( 2012). Chemical Education Transfer for Safe Practice Improvement Regarding Volatile Organic Solvents among Gasoline Station Workers, Bangkok, Thailand. Journal of Environment and Earth Science; 2(4): 1-7. ISSN 2224-3216 (Paper) ISSN 2225-0948 (Online)

[35]. Vastrad, J., Kotur, R., \& Byadgi, S. (2013). Occupational related health problems of workers in ginning mill. Asian Journal of Home Science (AJHS); 8 ( 2 ): 657-660.

[36]. Wall, J. (2009).Development of a health-belief-model-based instrument to assess worker beliefs about using personal protective equipment. A thesis submitted in partial fulfillment of the requirments for the degree of master of science. Faculty of science. University of Utah.

[37]. Yovi, E., \& Yamada, Y. (2015). Strategy to disseminate Occupational safety and health information to forestry workers. Journal of Tropical Forest Science 27(2): 213-221

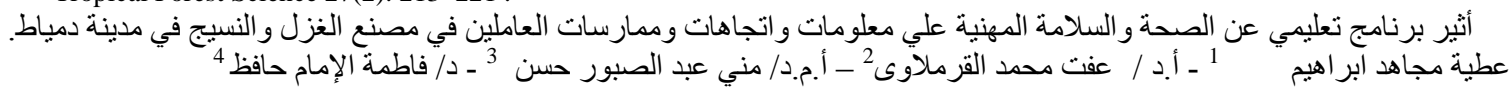




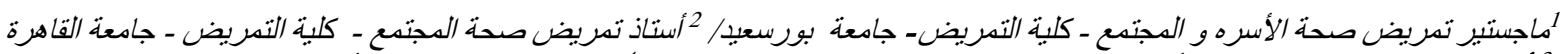

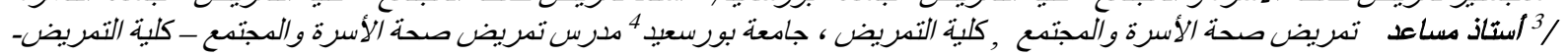

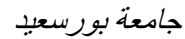

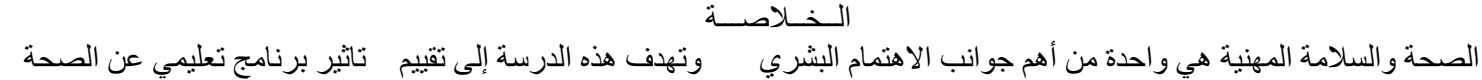

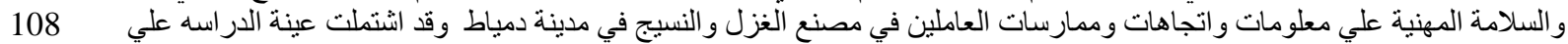

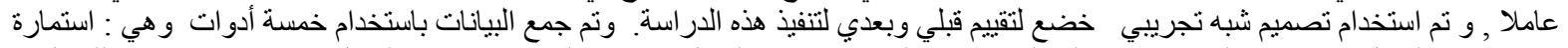

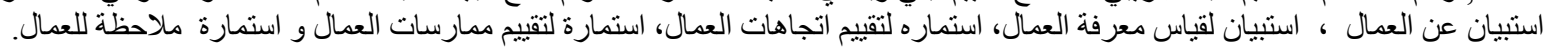

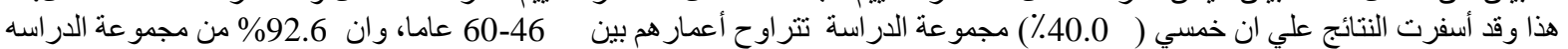

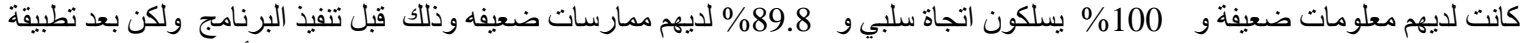

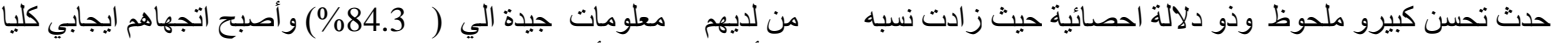

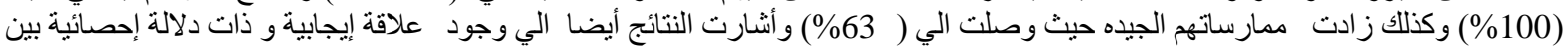

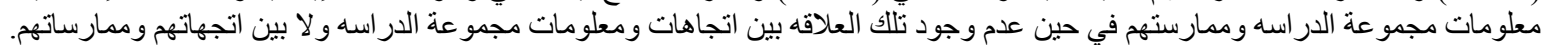

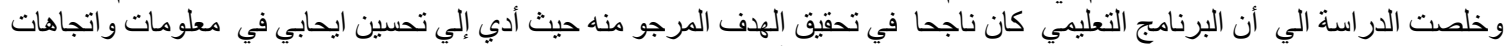

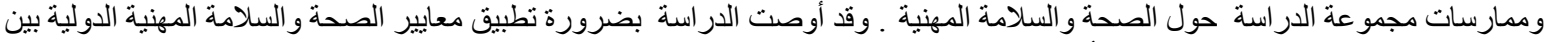

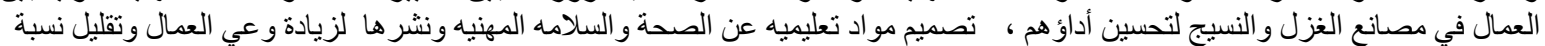

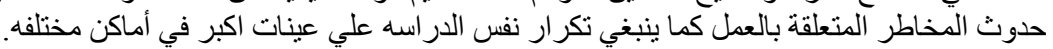

الكلمات الدالة المرشدة :الصحة والسلامة المهنبة بيرنامج تعلبي , مصنع الغزل و النسيج 